\title{
Sonochemical One-Step Synthesis of Polymer-Capped Metal Oxide Nanocolloids: Antibacterial Activity and Cytotoxicity
}

\author{
Anjani P. Nagvenkar, ${ }^{\dagger}$ Ilana Perelshtein, ${ }^{\dagger}$ Ylenia Piunno,,$^{\ddagger}$ Paride Mantecca, $\stackrel{+}{\ddagger}$ \\ and Aharon Gedanken*, ${ }^{\dagger} \bullet$
}

\author{
${ }^{\dagger}$ Department of Chemistry and Institute for Nanotechnology and Advanced Materials, Bar-Ilan University, Ramat-Gan 5290002, \\ Israel
}

${ }^{\ddagger}$ Department of Earth and Environmental Sciences, Research Center POLARIS, University of Milano-Bicocca, Milan 20126, Italy

\section{Supporting Information}

ABSTRACT: Most antibacterial agents demand their action in the form of a liquid for compatibility and ease of use in biosystems, which are mainly composed of biological fluids. Controlling the colloidal stability of metal oxide nanocolloids, in parallel with minimizing the effect of using a large amount of surfactant on their biocidal activity and cytotoxicity, remains a challenge. Here, we address the stability of nanocolloids of $\mathrm{ZnO}$ and $\mathrm{CuO}$ in the presence of polymer surfactants and the influence of the surface capping on their antibacterial activity and cytotoxicity. The metal oxide nanoparticles (NPs) were synthesized sonochemically in a single step and tested against both Gram-negative Escherichia coli and Gram-positive Staphylococcus aureus to validate their biocidal efficacy. Cytotoxicity studies were performed on human alveolar epithelial cells. Polyethylene glycol- and polyvinyl alcohol-capped NPs are observed to show the minimum cytotoxicity whereas polyethylene imine-capped and pristine metal oxide NPs are toxic to the mammalian cells. The cytotoxic and antibacterial properties of the stable nanocolloids displayed an inverse relation, highlighting the role and significance of the polymer capping. The nontoxic biocidal nanocolloids showed an effective antibacterial efficacy of $99.9 \%$ in $2 \mathrm{~h}$.

\section{INTRODUCTION}

Metal oxides are the most explored class of inorganic materials owing to their unique physical and chemical properties, controllable particle size, low synthesis cost, and high stability. ${ }^{1}$ The use of metal oxide nanoparticles (NPs), termed MONPs, has drawn immense attention in the biomedical field as a result of their biocompatibility, comparatively low toxicity, and reduced bacterial resistance. ${ }^{2-4}$ Their role as biocidal agents flourished, as they are considered biologically benign materials, which are relatively less hazardous to the environment and human health. $\mathrm{CuO}$ and $\mathrm{ZnO}$, being constituted by essential elements, are more biocompatible than other metal oxides and their toxicity is lower than, for example, silver- or nickel-based NPs. However, the presence of heavy elements raises the issues of cytotoxicity of these MONPs at higher concentrations. In addition, the stability of the NPs toward agglomeration is an important concern from the point of its applicability. ${ }^{5-8}$ Considering the primary issue of stability, the profound effect of the size of the NPs on the antibacterial activity of the MONPs renders importance to the stability of the NPs in solution. ${ }^{9}$ The use of a surfactant or capping agent proved to significantly prolong the lifespan of NPs in suspension by avoiding agglomeration. ${ }^{10,11}$ In addition, during synthesis, the presence of surfactant molecules in the reaction cell leads to the formation of smaller NPs, as nucleation occurs in the surfactant matrix, with immediate capping of the NPs by surfactant molecules, preventing further growth.

The cytotoxic nature of MONPs is also a matter of concern because of their potential effects on the human health and the environment. ${ }^{12,13}$ Reactive oxygen species (ROS) are considered the primary mechanistic pathway for the cellular oxidative stress resulting in biocidal activity of MONPs, and are therefore used to determine the level of toxicity. ${ }^{14}$ The current work focuses on both issues by synthesizing colloidal solutions of metal oxides in the presence of polymers as surfactants and studying their biocidal and cytotoxic properties. As most biological processes occur in an aqueous environment, the application of MONPs in the suspended colloidal form is crucial for better assimilation and functioning of these agents in biosystems. Colloidal solutions of NPs, termed nanocolloids, are thus most suitable for biological fluids. In order to achieve nanocolloids with higher stability and a homogenous dispersion of NPs, ultrasound-assisted synthesis was found to be an effective technique. ${ }^{4}$ Although nanocolloids of $\mathrm{CuO}$ and $\mathrm{ZnO}$ are widely exploited in varied areas of nanoscience, their application as antibacterial agents in the colloidal form was seldom explored. ${ }^{15-18}$ Khashan et al. tested the antibacterial

Received: January 20, 2019

Accepted: March 21, 2019

Published: August 12, 2019 

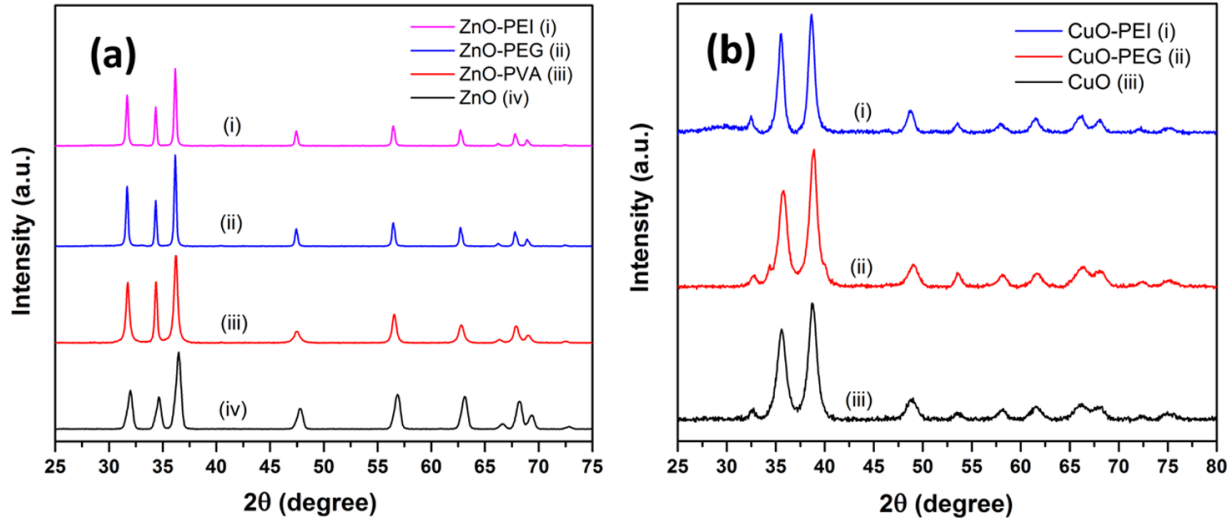

Figure 1. Representative XRD profiles of (a) ZnO-capped with (i) PEI, (ii) PEG, and (iii) PVA and (iv) pristine and (b) CuO-capped with (i) PEI (ii) PEG, and (iii) pristine.

activity of $\mathrm{CuO}$ suspension prepared by laser ablation of the copper metal pellet and reported a synergistic effect of the $\mathrm{CuO}$ NPs with the antibiotic amoxicillin. ${ }^{19}$ Mahapatra et al. prepared a $\mathrm{CuO}$ suspension by dispersing the as-synthesized $\mathrm{CuO}$ NPs in water in the absence of surfactants and conducted antibacterial and cytotoxicity studies. ${ }^{20}$ To our knowledge, there are no reports in the literature of antibacterial and cytotoxicity assays conducted on stable $\mathrm{CuO} /$ polymer nanocolloids with $\mathrm{CuO}$ NPs fabricated in situ in the polymer matrix using ultrasonication. In the case of $\mathrm{ZnO}$, despite countless reports on its antibacterial activity, only recently the biocidal properties were collated by our group following a one-step synthesis of colloidal $\mathrm{ZnO}$ by the sonochemical method, ${ }^{28}$ providing the highest stability of $\mathrm{ZnO}$ NPs reported so far.

Many studies addressed the toxic effects of $\mathrm{CuO}$ and $\mathrm{ZnO}$ NPs, suggesting possible hazardous effects in humans and other organisms. ${ }^{21}$ Although a large amount of toxicity data was collected, a debate is still open about the properties of these MONPs, in particular regarding their biological reactivity and adverse outcome pathways that are evoked. The size and shape of the NPs, as well as their crystalline structure, significantly influence the toxic behavior. Smaller and roundshaped $\mathrm{ZnO}$ NPs tend to display higher toxicity than bigger and rod-shaped particles. ${ }^{22,23}$ Similarly, for CuO NPs, the small size of the particles was pointed out as a main driver of cell toxicity, determining both higher bioavailability and enhanced intracellular reactivity, finally determining significant cytotoxic and genotoxic effects. ${ }^{24-26}$ In a previous study, we investigated not only the antibacterial efficacy but also the cytotoxic properties of differently synthesized $\mathrm{CuO}$ and $\mathrm{ZnO} \mathrm{NPs}$, which were observed to depend on the size and shape and, perhaps even more interestingly, on their crystalline structure.

The adverse effects of MONPs on nontarget cells and organisms vary according to the modalities by which the NPs interact with the biological systems; for example, size, shape, and agglomeration are able to modulate differently the endocytosis mechanism. ${ }^{28}$ At the same time, the protein corona effect can be modulated by the NP physicochemical characteristics as well as by the medium in which NPs are dispersed. $^{29}$ Doped or coated MONPs were seen to induce different toxicities in human cells, and it was put in relation to the decreased dissolution or to the more or less bioavailability, according to the surface identity acquired by the NPs. ${ }^{30}$ These modalities change according to the physicochemical properties of the NP, and today there is very active investigation aimed at lowering the adverse biological effects of MONPs by controlling the influencing factors, for example, the NP size, shape, and surface properties. Toxicity and biocompatibility studies on polymer-capped MONPs are therefore of high relevance.

The current study reports the first attempt, to the best of our knowledge, to synthesize MONP colloids by a facile one-step sonochemical method and concomitantly characterize their biological activity. Stability issues in the formed suspensions are obviated by using optimal amounts of polymer that serves as the capping agent. The surfactant-stabilized nanocolloids are compared with their pristine MONP counterparts, and the biocidal properties are discussed, along with the aspects related to the toxicity.

\section{RESULTS AND DISCUSSION}

Optical and Morphological Characterization. The surfactant-stabilized synthesis of $\mathrm{ZnO}$ and $\mathrm{CuO}$ nanocolloids was achieved in a single step using the well-established ultrasound technique. ${ }^{31}$ Three water-soluble surfactants were used-polyvinyl alcohol (PVA), polyethylene glycol (PEG), and polyethylenimine (PEI) in different weight ratios with respect to the precursor metal acetate. As the stability of a colloid grows with the amount of the capping agent surrounding the NP in the liquid matrix, a substantial amount of surfactant was used to impart maximal stability to the synthesized colloids; weight ratios of the surfactant to metal acetate were optimized, as mentioned in Table S1. Increasing the amount of surfactant above $30 \mathrm{wt} \%$ with respect to the metal salt precursor hindered complete formation of MONPs in the matrix. This was evidenced by the appearance of a translucent turbid liquid after addition of ammonia instead of opaque white $(\mathrm{ZnO})$ or dark brown $(\mathrm{CuO})$ colored colloids, indicating an incomplete reaction. The formation of $\mathrm{CuO}$ was not achieved in the PVA matrix because of the formation of a green-colored $\mathrm{Cu}$ (II)-PVA complex, ${ }^{32,33}$ which inhibited the hydrolysis of $\mathrm{Cu}^{2+}$ ions in the solution. As shown in Table S1, the amount of PEI is restricted to $5 \mathrm{wt} \%$ because of its basic nature, which raises the $\mathrm{pH}$ of the solution above 9. This leads to dissolution of the as-formed metal oxide NPs, impeding formation of a nanocolloid.

The crystallinity and structure of the synthesized metal oxides with different surfactants were analyzed by X-ray diffraction (XRD) (Figure 1). The peaks of $\mathrm{ZnO}$ and $\mathrm{CuO}$ correspond to the planes of hexagonal zincite and monoclinic tenorite, respectively, and match the Joint Committee for 
Powder Diffraction Studies (JCPDS) files no. 70-2551 and 410254, respectively. The bulk amount of polymer in the reaction mixture did not affect the crystallinity of the NPs. The formation of $\mathrm{ZnO}$ and $\mathrm{CuO} \mathrm{NPs}$ in the polymer matrix was further confirmed by recording UV-vis absorption spectra (Figure $\mathrm{S} 1$ ). The pristine $\mathrm{ZnO}$ shows an absorption peak at $364 \mathrm{~nm}$, while the surfactant-capped NPs exhibit peaks at lower wavelengths, indicating smaller particles. $\mathrm{ZnO}-\mathrm{PVA}$ displayed absorption peaks at 344 and $357 \mathrm{~nm}$, ascribed to $\mathrm{ZnO}$ NPs and $\mathrm{ZnO}-\mathrm{PVA}$ complex, respectively. ${ }^{31}$ Similarly, absorption peaks at 346 and $361 \mathrm{~nm}$ were observed for $\mathrm{ZnO}-$ $\mathrm{PEG}$ and $\mathrm{ZnO}-\mathrm{PEI}$, respectively; the higher absorption wavelength of the latter, indicating larger particles, can be imputed to the significantly lower amount of surfactant used. UV-vis spectra of the $\mathrm{CuO}$ colloids revealed a broad absorption region centered at 298, 287, and $276 \mathrm{~nm}$ for $\mathrm{CuO}, \mathrm{CuO}-\mathrm{PEG}$, and $\mathrm{CuO}-\mathrm{PEI}$, respectively (Figure $\mathrm{S} 1$ ). Thus, we can state that the blue shift in the absorption spectra of the polymer-capped NPs with respect to their pristine forms affirms that NPs with a smaller average size were formed in the presence of the capping agent.

The stability of the NPs in the colloid can be estimated from the zeta potentials, which assess the surface charge on the nanoparticle. Higher zeta potentials imply increased charge, and thus stronger electrostatic repulsion, preventing the colloidal NPs from coming in contact with each other and minimizing agglomeration. The zeta potentials of the polymercapped $\mathrm{ZnO}$ and $\mathrm{CuO}$ NPs are depicted in Figure 2. The lower

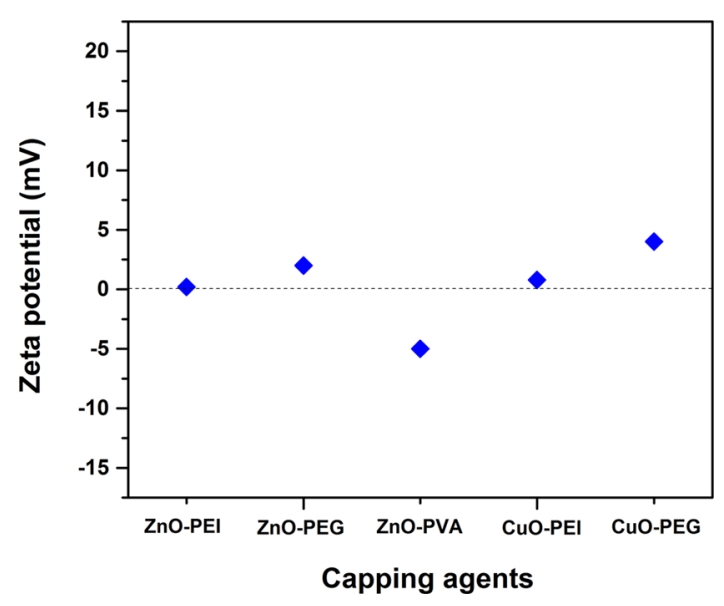

Figure 2. Zeta potentials for polymer-capped $\mathrm{ZnO}$ and $\mathrm{CuO}$ NPs. values observed for the PEI-capped NPs imply that they are less stable. $\mathrm{ZnO}-\mathrm{PEG}$ and $\mathrm{CuO}-\mathrm{PEG}$ exhibited good stability over a period of 40 days, compared to the other surfactantstabilized nanocolloids, in agreement with the zeta potentials observed for these samples. The pristine $\mathrm{ZnO}$ and $\mathrm{CuO}$ NPs synthesized in the absence of surfactant agglomerate and precipitate within $1 \mathrm{~h}$ of sonication.

Antibacterial Activity and Mechanism. The antibacterial properties of the polymer-capped $\mathrm{ZnO}$ and $\mathrm{CuO}$ nanocolloids are demonstrated against two types of bacterial strains: Escherichia coli (Gram-negative) and Staphylococcus aureus (Gram-positive). The killing kinetics for both strains of bacteria were monitored by the culturing $(\mathrm{CFU} / \mathrm{mL})$ method. The biocidal activity of the synthesized nanocolloids (tested at a concentration of $0.5 \mathrm{mg} / \mathrm{mL}$ ) is represented in Figures 3 and 4. For E. coli, $\mathrm{CuO}-\mathrm{PEG}$ and $\mathrm{ZnO}-\mathrm{PVA}$ demonstrated $99.9 \%$ bacterial killing after $120 \mathrm{~min}$ of exposure, while $\mathrm{CuO}-\mathrm{PEI}$ and $\mathrm{ZnO}-\mathrm{PEG}$ were less active. $\mathrm{ZnO}, \mathrm{ZnO}-\mathrm{PEI}$, and $\mathrm{CuO}$ showed 1, 1, and $2 \log$ reduction, respectively, after $180 \mathrm{~min}$ exposure to the bacteria. Similarly, for $S$. aureus, CuO-PEG showed complete reduction after $120 \mathrm{~min}$, whereas the same was observed for $\mathrm{ZnO}-\mathrm{PVA}$ and $\mathrm{CuO}-\mathrm{PEI}$ after $180 \mathrm{~min}$ of exposure. $\mathrm{ZnO}, \mathrm{CuO}$, and $\mathrm{ZnO}-\mathrm{PEI}$ were found to exhibit lower antibacterial efficacy. The higher resistance of $S$. aureus, compared with E. coli, is ascribed to the thick peptidoglycan layer in the cell wall of $S$. aureus, making it less susceptible to the action of the MONPs. ${ }^{34,35}$ Therefore, the observed higher antibacterial activity of $\mathrm{CuO}$ than $\mathrm{ZnO}$ was also validated previously and is in accordance with the present study. ${ }^{36}$

The most plausible mechanism for the effective biocidal activity of the metal oxides is believed to be the generation of ROS, which are a class of free radical species of oxygen. ${ }^{37,38}$ These strong oxidants cause oxidative stress in the cell, damaging the cellular components and leading to cell disruption and death. ${ }^{39}$ Assuming that a similar mechanism is responsible for the activity observed, correlation between generated ROS and the particle size of the NPs is developed. Electron spin resonance (ESR) is a widely used tool for detection of free radicals, in particular for measurement of ROS using 5,5-dimethyl-1-pyrroline- $\mathrm{N}$-oxide (DMPO) as a spin trap. ${ }^{40}$ DMPO captures ${ }^{\circ} \mathrm{OH}$ and superoxide anions, giving a quadrant signal arising from DMPO-OH and DMPO$\mathrm{OOH}$, respectively. Using equal concentrations of DMPO and the samples, comparison is based on the intensity of the quartet signal. The higher the signal intensity, the higher is the production of ROS by the NP. Figure 5 presents the quartet
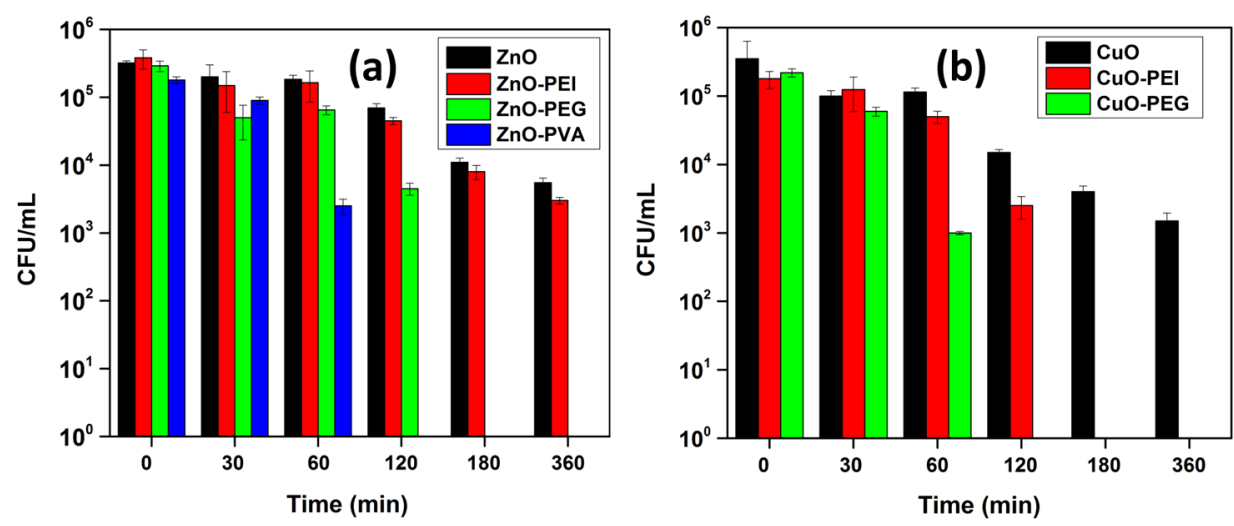

Figure 3. Antibacterial activity of pristine and surfactant-stabilized nanocolloids of (a) $\mathrm{ZnO}$ and (b) $\mathrm{CuO}$ against E. coli. 

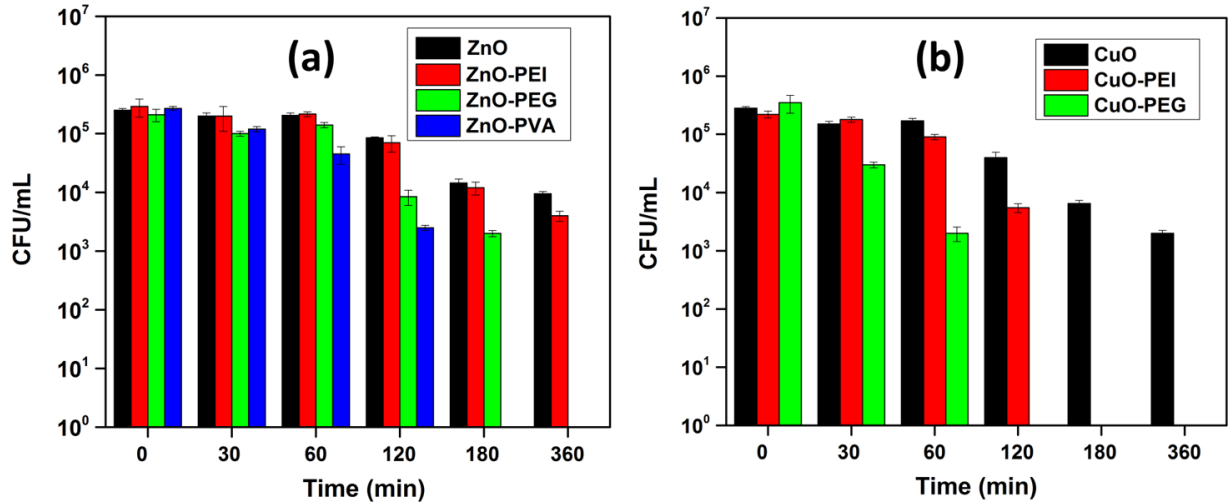

Figure 4. Antibacterial activity of pristine and surfactant-stabilized nanocolloids of (a) $\mathrm{ZnO}$ and (b) $\mathrm{CuO}$ against S. aureus.
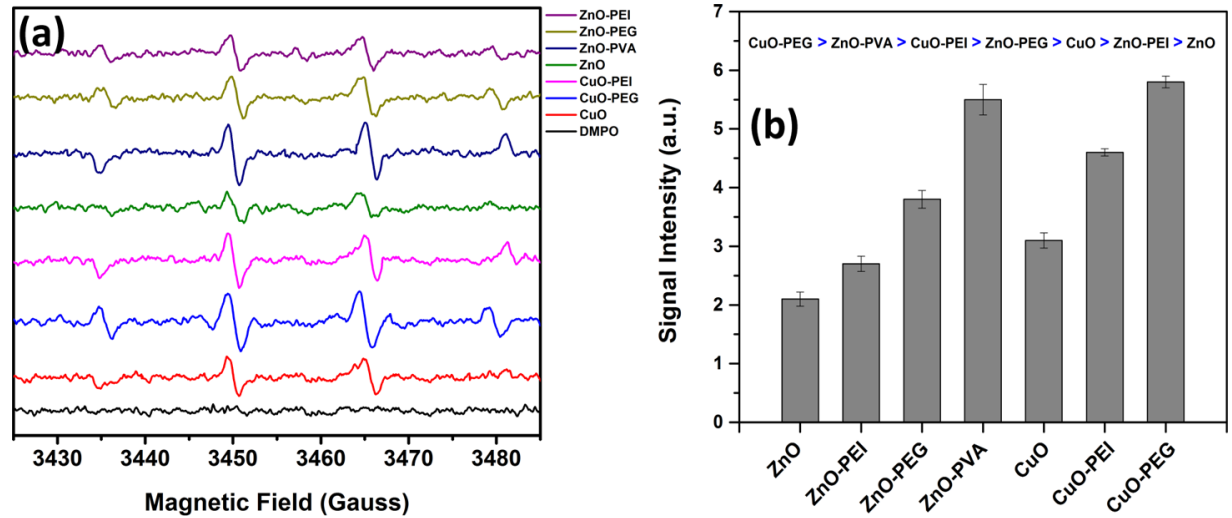

Figure 5. ESR spectra demonstrating (a) relative ROS production by $\mathrm{ZnO}$ and $\mathrm{CuO}$ NPs in the surfactant matrix and (b) integrated area depicting signal intensity of the generated ROS.
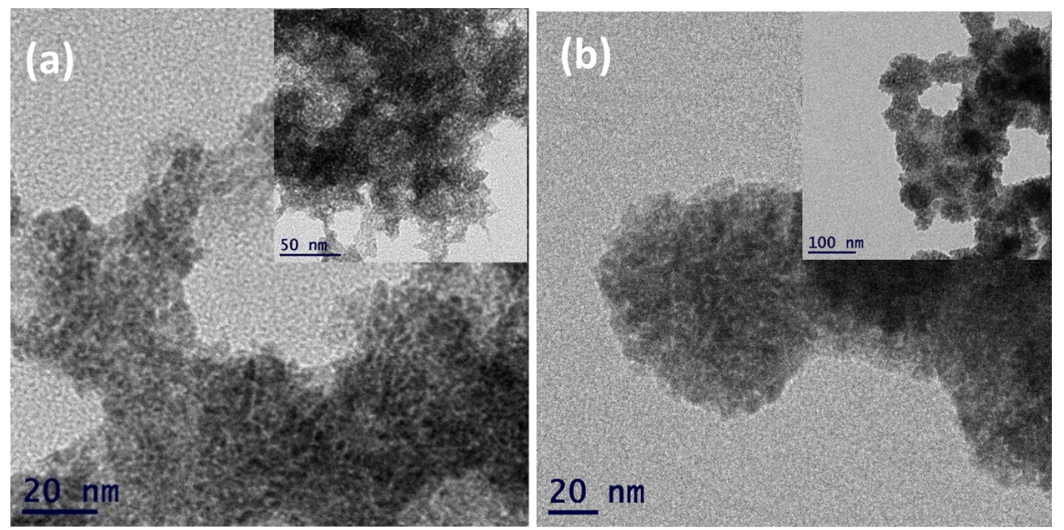

Figure 6. TEM images of the colloidal NPs: (a) CuO-PEG and (b) ZnO-PVA. Inset shows the low magnification images of the samples.

ESR signals and signal intensities of the ROS generated by the nanocolloids. The relative amounts of ROS produced by the samples are: $\mathrm{CuO}-\mathrm{PEG}>\mathrm{ZnO}-\mathrm{PVA}>\mathrm{CuO}-\mathrm{PEI}>\mathrm{ZnO}-$ $\mathrm{PEG}>\mathrm{CuO}>\mathrm{ZnO}-\mathrm{PEI}>\mathrm{ZnO}$. The ESR results favor the biocidal activity rendered by the capped metal oxide colloids, wherein higher ROS accounts for faster killing of the bacteria by the nanocolloid. Thus, the bacterial survival rate is observed to decrease with the increase in total ROS concentration.

Having affirmed that the expected mechanism of ROS generation is indeed responsible for the effective antibacterial potency of the nanomaterials, the source and enhancement in its production are further elucidated in detail. The primary source of ROS formation is the presence of lattice defect sites in the nanomaterial; these sites serve as active spots for adsorption of water molecules and their dissociation, generating oxygen radicals. ${ }^{27,41}$ The present study in which metal oxide nanocolloids were synthesized using ultrasound supports this finding. The acoustic energy from the sonication process during nucleation of the metal oxide crystal introduces defects and dislocations, yielding a highly perturbed nanocrystal. $^{31,42}$ The size of the NP also has a profound effect on the amount of ROS generated by the nanomaterial. Compared to the bulk particle, the NP has a higher surface area and thus higher surface reactivity for ROS production. ${ }^{43}$ The particle sizes of the NPs reported here, along with the ESR signal intensity of the ROS, are in accordance with the observed 

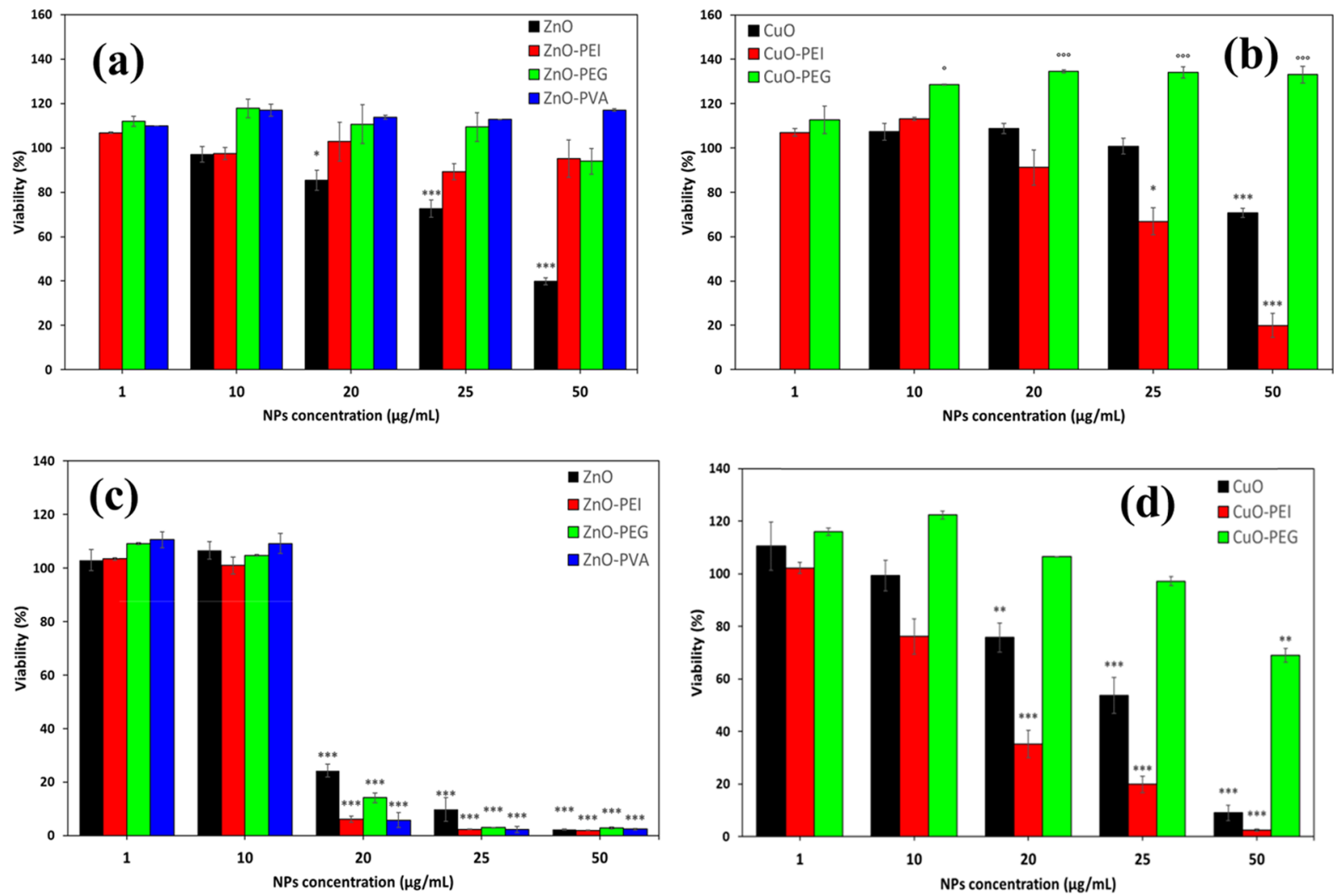

Figure 7. Cytotoxicity of pristine and surfactant-stabilized nanocolloids. Cell viability was measured by the [3-(4,5-dimethylthiazol-2-yl)-2,5diphenyltetrazolium bromide] MTT assay. (a,b) Effects of $\mathrm{ZnO}$ and $\mathrm{CuO}$ NPs after $3 \mathrm{~h}$ exposure and (c,d) effects of $\mathrm{ZnO}$ and $\mathrm{CuO}$ NPs after $24 \mathrm{~h}$ exposure.

bactericidal efficiency of these nanocolloids. A Table S2 summarizes the average particle sizes and the corresponding zeta potential values. The lowest particle sizes of $\sim 6$ and $\sim 7$ $\mathrm{nm}$ are displayed by $\mathrm{CuO}-\mathrm{PEG}$ and $\mathrm{ZnO}-\mathrm{PVA}$, respectively (Figures 6 and S2). These samples indeed show the highest ROS production and clearly exhibit the best antibacterial efficacy among the NPs. Pristine $\mathrm{ZnO}$ and $\mathrm{CuO}$, without stabilizing agents, have the largest particle size, which might be responsible for their reduced antibacterial activity.

Cytotoxicity of the Nanocolloids. Cytotoxicity was measured in human A549 cells exposed to the colloidal $\mathrm{ZnO}$ and $\mathrm{CuO}$ NPs for 3 and $24 \mathrm{~h}$; results are shown in Figure 7. It is clear that with the exception of $\mathrm{CuO}-\mathrm{PEI}$, which revealed higher toxicity than pristine $\mathrm{CuO}$, all colloidal $\mathrm{ZnO}$ and $\mathrm{CuO}$ NPs are less cytotoxic than the corresponding pristine NPs after both $3 \mathrm{~h}$ (Figure 7a,b) and $24 \mathrm{~h}$ (Figure 7c,d).

The polymer capping of the $\mathrm{ZnO}$ NPs resulted in less effective modulation of the cytotoxicity, as after $24 \mathrm{~h}$ exposure all $\mathrm{ZnO}$ nanocolloids were strongly cytotoxic at concentrations $\geq 20 \mathrm{ppm}$, while no effects were measured for pristine and surfactant-capped $\mathrm{ZnO}$ exposure to $\leq 10 \mathrm{ppm}$ (Figure $6 \mathrm{c}$ ). After $3 \mathrm{~h}$ of exposure, the $\mathrm{ZnO}$ nanocolloids demonstrated lower cytotoxicity with respect to pristine $\mathrm{ZnO}$ (Figure 6a); it is noteworthy that $\mathrm{ZnO}-\mathrm{PVA}$ did not induce any decrease in cell viability even at the highest concentration tested, confirming PVA capping as the most promising approach for safer $\mathrm{ZnO}$ NPs.

Regarding $\mathrm{CuO}$, stabilization with PEI conferred an augmented cytotoxic potential to the NPs, as demonstrated by the significant and concentration-dependent decrease in cell viability at both 3 and $24 \mathrm{~h}$ exposures (Figure 6b,d). On the contrary, $\mathrm{CuO}-\mathrm{PEG}$ was only slightly cytotoxic, as a significant decrease in cell viability was observed only after $24 \mathrm{~h}$ exposure at very high $(50 \mathrm{ppm})$ concentration (Figure 6d). After $3 \mathrm{~h}$, pristine $\mathrm{CuO}$ was already cytotoxic, while $\mathrm{CuO}-\mathrm{PEG}$ was not, and during the $3 \mathrm{~h}$, it even induced a slight increase in cell metabolism (Figure 6b). After $24 \mathrm{~h}$ exposure, the cytotoxicity of $\mathrm{CuO}$ was significantly rescued by PEGylation (Figure 6d), as cell viability did not significantly decrease even with respect to the control until the highest exposure concentration of $50 \mathrm{ppm}$.

From the toxicity studies, we can conclude that the polymer stabilization of the NP suspensions was very effective in modulating the cytotoxic properties of $\mathrm{CuO}$, while for $\mathrm{ZnO}$ it was less effective. PEI coating makes the $\mathrm{CuO}$ NPs more cytotoxic, while PEGylation renders them safer.

Comparison between the Cytotoxicity and Antibacterial Results. Decreasing antibacterial activity due to decreased ROS generation

$$
\begin{aligned}
& \mathrm{CuO}-\mathrm{PEG}>\mathrm{ZnO}-\mathrm{PVA}>\mathrm{CuO}-\mathrm{PEI}>\mathrm{ZnO}-\mathrm{PEG}>\mathrm{CuO} \\
& \quad>\mathrm{ZnO}-\mathrm{PEI}>\mathrm{ZnO}
\end{aligned}
$$

Decreasing cytotoxicity after $3 \mathrm{~h}$ at $25 \mathrm{ppm}$ concentration (increasing cell viability)

$$
\mathrm{CuO}-\mathrm{PEI}>\mathrm{ZnO}-\mathrm{PEI}>\mathrm{ZnO}-\mathrm{PEG}>\mathrm{ZnO}-\mathrm{PVA}>\mathrm{CuO}-\mathrm{PEG}
$$

Decreasing cytotoxicity after $24 \mathrm{~h}$ at $25 \mathrm{ppm}$ concentration (increasing cell viability)

$$
\mathrm{ZnO}-\mathrm{PEI}>\mathrm{ZnO}-\mathrm{PEG}>\mathrm{ZnO}-\mathrm{PVA}>\mathrm{CuO}-\mathrm{PEI}>\mathrm{CuO}-\mathrm{PEG}
$$

The higher cytotoxicity of the MONPs with PEI as the surfactant is in accordance with the significantly lower amount 
of surfactant used, leading to increased exposure of the NPs to the cell surface. Moreover, PEI was recognized as an agent that promotes cell penetration and is commonly used as a gene delivery agent owing to its high transfection efficiency; it is also known to interact with the negatively charged cell surface, promoting its attachment to the cell and cell uptake. ${ }^{44,45}$ The fact that at $3 \mathrm{~h}$ of exposure, PEI is able to enhance the cytotoxic properties of $\mathrm{CuO}$ NPs but not those of $\mathrm{ZnO}$ NPs can be justified by the following claim. According to the proton-sponge effect, it can induce a lysosomal escaping effect, which finally may determine an increase of MONPs free in the cytoplasm, where they can induce oxidative damages to the intracellular membrane systems. It was demonstrated that in the water aqueous environment, sonochemically synthesized $\mathrm{CuO}$ NPs produce more ROS than $\mathrm{ZnO}$ NPs. If in the presence of PEI, they are released from the endolysosomal compartments, without massive dissolution (and it likely occurs during short-term exposure, e.g. $3 \mathrm{~h}$ ), $\mathrm{CuO}$ NPs may induce higher oxidative damages to protein and lipid membrane domains, culminating in a significant decrease in cell viability. At prolonged exposure time $(24 \mathrm{~h})$, the extracellular and intracellular dissolution of $\mathrm{CuO}$ and $\mathrm{ZnO}$ NPs become the main determinant of the induced toxicity, masking the effect of the polymers used. This is particularly relevant for $\mathrm{ZnO} N P s$, which dissolve easier than $\mathrm{CuO}$ ones, ending up in comparable cytotoxic effects of $\mathrm{ZnO}$ colloidal suspensions produced with the different polymers. However, the speculations need additional experimental evidences to be proved and are of interest for future study. The novel nanomaterial $\mathrm{CuO}-\mathrm{PEI}$, which combines the high surface reactivity of the $\mathrm{CuO}$ NPs with the unique properties of the PEI surface coating, could potentially be useful in selective killing of human cells undergoing uncontrolled proliferation.

Regarding the safety of the antibacterial metal oxide nanocolloids, the results highlight $\mathrm{CuO}-\mathrm{PEG}$ as the most promising material capable of preserving cell viability, followed by $\mathrm{ZnO}-\mathrm{PVA}$.

It is interesting to note that, with the exclusion of the PEIcapped NPs, the cytotoxicity follows an inverse relation with the antibacterial activity and ROS generation capacity of the MONPs in a cell-free environment. To explain these interesting experimental results, more research on the toxicity mechanisms in both bacterial and human cells is required.

At the moment, based on the literature, we can speculate that PEG surface coating of the $\mathrm{CuO}$ NPs could have influenced their cellular internalization and successive intracellular reactivity. It is known that PEG functional coating of different NPs determines their cellular uptake and internalization. $^{46,47}$ In addition, on account of its biocompatibility, PEGyaltion of NPs is a reported strategy to minimize the nanotoxicity of the particles, with diminished impact on cell viability. This is because PEG on the surface prevents the particle opsonization by the proteins present in the body fluids or in the cell culture media, which has been seen to enhance NP uptake by receptor-mediated endocytosis (thus preventing phagocytosis by specialized immune cells). ${ }^{48}$ Hence, also in the present work, PEGylation may have determined a lower internalization of $\mathrm{CuO}$ NPs in human cells, justifying the low toxicity even in the presence of highly reactive NPs. On the contrary, it is demonstrated that the mechanism at the base of the antibacterial activity of $\mathrm{CuO}$ NPs is related to the contact at the cell surface level and the consequent oxidative stress leading to the cell death. Together with the high capability of mammalian cells to efficiently buffer oxidative stress by a complex intracellular enzymatic system, ${ }^{49,50}$ the current results may justify the increased safety of $\mathrm{CuO}-\mathrm{PEG}$ toward mammalian cells, while being strongly toxic toward bacterial cells. $^{51,52}$

The less effective results achieved with polymer coating of $\mathrm{ZnO}$ NPs, including PEGylation, with respect to $\mathrm{CuO}$ NPs, may be attributed to the different cytotoxic mechanism of these two metal oxides. For $\mathrm{CuO}$, a significant role in the toxicity toward mammalian cells is played by the particle surface reactivity-PEGylated $\mathrm{CuO}$ showed the lowest cytoxicity, followed by the PEI-coated and pristine $\mathrm{CuO}$ NPs. For $\mathrm{ZnO}$, on the other hand, a major role was attributed to the $\mathrm{Zn}$ ion dissolution both extra- and intracellularly. ${ }^{53}$ The intracellular dissolution of the $\mathrm{ZnO} \mathrm{NPs}$, which determines the cytotoxicity of the $\mathrm{ZnO}$, increases with the concentration of the NPs and shows a profound effect at concentrations higher than $10 \mu \mathrm{g} / \mathrm{mL} .^{54}$ The solubility product constant $\left(K_{\mathrm{sp}}\right)$ of $\mathrm{CuO}$ is around $10^{-22}$ at room temperature, meaning that there are effectively no ions of $\mathrm{Cu}^{2+}$ in the solution (the concentration of $\mathrm{Cu}$ ions is $10^{-11} \mathrm{M}$ ). On the other hand, the $K_{\mathrm{sp}}$ of $\mathrm{ZnO}$ is much higher-around $10^{-10}$, yielding $10^{-5}$ mol per liter of $\mathrm{Zn}^{2+}$. This significant solubility could explain the higher cytotoxicity of $\mathrm{ZnO}$.

\section{CONCLUSIONS}

In conclusion, we have demonstrated antibacterial and cytotoxic studies conducted on stable $\mathrm{ZnO}$ and $\mathrm{CuO}$ nanocolloids synthesized using a high amount of surfactant. The sonochemical method reported is unique and feasible to scale up preparation of metal oxide nanocolloids for wide use as antibacterial agents. The present results confirm the crucial role of polymer capping in mitigating the effect of NPs on mammalian cells, while still exhibiting notable antibacterial effects. The current study also affirms the role and significance of the type of polymer used as the capping agent in deciding the overall cytotoxicity of the samples. PEI is observed to enhance toxicity, whereas PEGylation of the NPs reduces the toxic effect. Finally, solubility of the MONPs is a decisive factor in their cytotoxicity- $\mathrm{ZnO}$ is much more soluble than $\mathrm{CuO}$, offering a plausible explanation of the higher toxicity of $\mathrm{ZnO}-\mathrm{PEG}$ relative to $\mathrm{CuO}-\mathrm{PEG}$.

\section{EXPERIMENTAL SECTION}

$\mathrm{Zn}$ (II) acetate dihydrate, $\mathrm{Cu}(\mathrm{II})$ acetate monohydrate, poly(vinyl alcohol) (PVA) MW $=88-98 \mathrm{~K}, \mathrm{PEG} \mathrm{MW}=6 \mathrm{~K}$, and PEI branched $50 \% \mathrm{w} / \mathrm{v}$ in $\mathrm{H}_{2} \mathrm{O} \mathrm{MW}=75 \mathrm{~K}$ were purchased from Sigma-Aldrich and used as received without further purification. The precursor salts and polymers were separately dissolved in deionized water. The two solutions were mixed together to obtain a total volume of $100 \mathrm{~mL}$. The concentration of metal ions was maintained at $0.01 \mathrm{M}$, and the weight ratios of the metal acetate to polymer were $1: 5$ for $\mathrm{Cu}$ (acetate) $\cdot \mathrm{H}_{2} \mathrm{O} / \mathrm{PEI}$ and $\mathrm{Zn}$ (acetate) $\cdot 2 \mathrm{H}_{2} \mathrm{O} / \mathrm{PEI}$ and $1: 30$ for the rest. The obtained solution of metal ions with the dissolved polymer was irradiated with an ultrasonic probe ( $\mathrm{Ti}-$ horn@20 kHz, $100 \mathrm{~W} \mathrm{~cm}^{-2}$ ). The temperature was allowed to rise, and upon reaching $60^{\circ} \mathrm{C}, \sim 0.2 \mathrm{~mL}$ of an aqueous solution of ammonium hydroxide $(28-30 \%)$ was introduced into the reaction mixture to achieve a $\mathrm{pH}$ of $\sim 8$. Completion of the reaction was indicated by color change-from colorless to white and from bluish-green to dark brown for $\mathrm{ZnO}$ and $\mathrm{CuO}$, 
respectively, confirming the formation of MONPs in the colloidal polymer matrix. Sonication was continued for $30 \mathrm{~min}$, and the mixture was chilled in an ice bath to maintain a reaction temperature of $25{ }^{\circ} \mathrm{C}$. Pristine $\mathrm{ZnO}$ and $\mathrm{CuO}$ in suspension were synthesized by following the same procedure in the absence of polymers.

Characterization. XRD patterns for $\mathrm{ZnO}$ and $\mathrm{CuO}$ were obtained using a Bruker D8 ADVANCE X-107 X-ray diffractometer using $\mathrm{Cu} \mathrm{K} \alpha(\lambda=1.5418 \AA)$ as the source. Zeta potential was performed on a Nano ZS Malvern Zetasizer instrument. High-resolution transmission electron microcopy (HR-TEM) images were obtained using a JEOL JEM-2100 model operated at an accelerated voltage of $200 \mathrm{kV}$. The absorption spectrum of the $\mathrm{ZnO}-\mathrm{PVA}$ nanofluid was recorded on a CARY Bio 100 spectrophotometer (Varian, Australia). The metal oxide concentration in the colloid was determined by inductively coupled plasma analysis. The amount of generated ROS was determined by ESR using a 121 Bruker EPR 100d X-band spectrometer with DMPO as a spin trap. To $80 \mu \mathrm{L}$ of the colloidal sample, $20 \mu \mathrm{L}$ of DMPO $(0.01 \mathrm{M})$ was added, and the solution was drawn by a syringe into a gaspermeable Teflon capillary. The capillary was folded twice, inserted into a narrow quartz tube open at both ends, and placed in the ESR cavity. The blank was measured by replacing the sample with deionized water.

Antibacterial Assay. The antibacterial activities of the synthesized metal oxide colloids with different capping agents were tested against two common strains of bacteria, namely Gram-negative E. coli and Gram-positive S. aureus. The antibacterial activity of these different nanocolloids was investigated using the colony-forming units per $\mathrm{mL}$ (CFU/ $\mathrm{mL}$ ) method. Strains of both bacteria were aerobically grown by incubating overnight at $37{ }^{\circ} \mathrm{C}$ in Luria Bertani (LB) broth. Following incubation, $0.2 \mathrm{~mL}$ aliquots were transferred to 10 $\mathrm{mL}$ of fresh $\mathrm{LB}$ broth and incubated at $37^{\circ} \mathrm{C}$ for a further $3 \mathrm{~h}$. The culture was further diluted 3 -fold in LB broth to yield a bacterial suspension with a density of $10^{5} \mathrm{CFU} / \mathrm{mL}$. Time-kill experiments were conducted by adding $500 \mu \mathrm{L}$ of nanocolloid solution $(0.5 \mathrm{mg} / \mathrm{mL})$ to $500 \mu \mathrm{L}$ of bacterial suspension. The suspensions were shaken on a rotary shaker at $200 \mathrm{rpm}$ and simultaneously incubated at $37^{\circ} \mathrm{C}$. After every $30 \mathrm{~min}, 100 \mu \mathrm{L}$ aliquots were taken from each sample, diluted 10 -fold in $10 \%$ LB medium, and transferred to nutrient agar plates. The plates were incubated at $37{ }^{\circ} \mathrm{C}$ for $16 \mathrm{~h}$ and counted for viable bacteria.

Cytotoxicity. Aqueous NP suspensions used for cytotoxicity studies were obtained by diluting the stock colloidal suspensions in the cell culture medium to obtain final concentrations of $1,10,20,25$, and $50 \mu \mathrm{g} / \mathrm{mL}$ of $\mathrm{ZnO}$ and $\mathrm{CuO}$. The suspensions of pristine $\mathrm{ZnO}$ and $\mathrm{CuO}$ were obtained by diluting the NP powders in ultrapure (MQ) water to obtain stock suspensions of $2 \mathrm{mg} / \mathrm{mL}$, which were sonicated for $30 \mathrm{~min}$ in an ultrasonic bath (Sonica Ultrasonic Extractor, Soltec, Italy). Aliquots from the stock solution were prediluted in MQ water (20-fold intermediate stock solution of NPs) and added to microplate wells containing serum-free OptiMEM medium to achieve the same NP test concentrations used for the colloidal suspensions.

The cell viability assay was performed following routine procedures established in our lab, as reported by Moschini et al. ${ }^{25}$ Human alveolar epithelial cells, ATCC A549 (American Type Culture Collection), were routinely maintained in culture. For cell viability assays, cells were seeded $\left(8 \times 10^{5}\right)$ in six multiwell plates and exposed to NP suspensions for 3 and $24 \mathrm{~h}$. Untreated cells were used as the control. At the end of treatments, cells were rinsed, and MTT [3-(4,5-dimethylthiazol-2-yl)-2,5-diphenyltetrazolium bromide] was added over 3 $\mathrm{h}$ to a final concentration of $0.0625 \mathrm{mg} / \mathrm{mL}$ in OptiMEM with $10 \%$ fetal bovine serum (FBS). The medium was removed, and the purple MTT reduction product (formazan crystals) was dissolved in DMSO. The absorbance of each sample, proportional to cell viability, was measured with a MultiskanAscent multiplate reader spectrophotometer (Thermo Fisher Scientific Inc., USA) at $570 \mathrm{~nm}$ using $690 \mathrm{~nm}$ as the reference wavelength. Cell viability was expressed as OD mean percent $( \pm S E)$. Statistical differences were tested by one-way ANOVA followed by Dunnett's test after evaluating the homogeneity of the variances among the treatment groups with the Levene test. Otherwise, for groups whose variances were found to be nonhomogeneous, statistical differences were tested with the Student's t-test followed by Bonferroni's test.

\section{ASSOCIATED CONTENT}

\section{Supporting Information}

The Supporting Information is available free of charge on the ACS Publications website at DOI: 10.1021/acsomega.9b00181.

UV visible spectra and TEM images of the metal oxide nanocolloids, and tables of weight ratio, zeta potential, and particle size (PDF)

\section{AUTHOR INFORMATION}

\section{Corresponding Author}

*E-mail: gedanken@mail.biu.ac.il.

ORCID

Paride Mantecca: 0000-0002-6962-049X

Aharon Gedanken: 0000-0002-1243-2957

Notes

The authors declare no competing financial interest.

\section{REFERENCES}

(1) Hahn, Y.-B.; Ahmad, R.; Tripathy, N. Chemical and Biological Sensors Based on Metal Oxide Nanostructures. Chem. Commun. 2012, 48, 10369-10385.

(2) Mamonova, I. A.; Babushkina, I. V.; Norkin, I. A.; Gladkova, E. V.; Matasov, M. D.; Puchin'yan, D. M. Biological Activity of Metal Nanoparticles and Their Oxides and Their Effect on Bacterial Cells. Nanotechnol. Russ. 2015, 10, 128-134.

(3) Yadavalli, T.; Shukla, D. Role of Metal and Metal Oxide Nanoparticles as Diagnostic and Therapeutic Tools for Highly Prevalent Viral Infections. Nanomed. Nanotechnol. Biol. Med. 2017, $13,219-230$.

(4) Stankic, S.; Suman, S.; Haque, F.; Vidic, J. Pure and Multi Metal Oxide Nanoparticles: Synthesis , Antibacterial and Cytotoxic Properties. J. Nanobiotechnol. 2016, 14, 1-20.

(5) Chen, J.; Zhu, J.; Cho, H.-H.; Cui, K.; Li, F.; Zhou, X.; Rogers, J.; Wong, S.; Huang, X. Differential Cytotoxicity of Metal Oxide Nanoparticles. J. Exp. Nanosci. 2008, 3, 321-328.

(6) Brayner, R.; Ferrari-Iliou, R.; Brivois, N.; Djediat, S.; Benedetti, M. F.; Fiévet, F. Toxicological Impact Studies Based on Escherichia Coli Bacteria in Ultrafine $\mathrm{ZnO}$ Nanoparticles Colloidal Medium. Nano Lett. 2006, 6, 866-870.

(7) Herman, D.; Walz, J. Y. Effects of Metal Oxide Nanoparticles on the Stability of Dispersions of Weakly Charged Colloids. Langmuir 2015, 31, 4844-4852. 
(8) Li, C.-C.; Chang, M.-H. Colloidal Stability of $\mathrm{CuO}$ Nanoparticles in Alkanes via Oleate Modifications. Mater. Lett. 2004, 58, 3903-3907.

(9) Stankus, D. P.; Lohse, S. E.; Hutchison, J. E.; Nason, J. A. Interactions between Natural Organic Matter and Gold Nanoparticles Stabilized with Different Organic Capping Agents. Environ. Sci. Technol. 2011, 45, 3238-3244.

(10) Loosli, F.; Stoll, S. Effect of Surfactants, $\mathrm{pH}$ and Water Hardness on the Surface Properties and Agglomeration Behavior of Engineered $\mathrm{TiO}_{2}$ Nanoparticles. Environ. Sci.: Nano 2017, 4, 203211.

(11) Zaccone, A.; Wu, H.; Lattuada, M.; Morbidelli, M. Correlation between Colloidal Stability and Surfactant Adsorption/Association Phenomena Studied by Light Scattering. J. Phys. Chem. B 2008, 112, 1976-1986.

(12) Ajitha, B.; Kumar Reddy, Y. A.; Reddy, P. S.; Jeon, H.-J.; Ahn, C. W. Role of Capping Agents in Controlling Silver Nanoparticles Size, Antibacterial Activity and Potential Application as Optical Hydrogen Peroxide Sensor. RSC Adv. 2016, 6, 36171-36179.

(13) Granata, G.; Yamaoka, T.; Pagnanelli, F.; Fuwa, A. Study of the Synthesis of Copper Nanoparticles: The Role of Capping and Kinetic towards Control of Particle Size and Stability. J. Nanopart. Res. 2016, $18,133$.

(14) Kaweeteerawat, C.; Ivask, A.; Liu, R.; Zhang, H.; Chang, C. H.; Low-Kam, C.; Fischer, H.; Ji, Z.; Pokhrel, S.; Cohen, Y.; et al. Toxicity of Metal Oxide Nanoparticles in Escherichia Coli Correlates with Conduction Band and Hydration Energies. Environ. Sci. Technol. 2015, 49, 1105-1112.

(15) Shahmiri, M.; Ibrahim, N. A.; Shayesteh, F.; Asim, N.; Motallebi, N. Preparation of PVP-Coated Copper Oxide Nanosheets as Antibacterial and Antifungal Agents. J. Mater. Res. 2013, 28, 31093118.

(16) Ahrari, F.; Eslami, N.; Rajabi, O.; Ghazvini, K.; Barati, S. The Antimicrobial Sensitivity of Streptococcus Mutans and Streptococcus Sangius to Colloidal Solutions of Different Nanoparticles Applied as Mouthwashes. Dent. Res. J. 2015, 12, 44-49.

(17) Ismail, R. A.; Ali, A. K.; Ismail, M. M.; Hassoon, K. I. Preparation and Characterization of Colloidal $\mathrm{ZnO}$ Nanoparticles Using Nanosecond Laser Ablation in Water. Appl. Nanosci. 2011, 1, 45-49.

(18) Beyth, N.; Houri-Haddad, Y.; Domb, A.; Khan, W.; Hazan, R. Alternative Antimicrobial Approach: Nano-Antimicrobial Materials. J. Evidence-Based Complementary Altern. Med. 2015, 2015, 246012.

(19) Khashan, K. S.; Sulaiman, G. M.; Abdulameer, F. A. Synthesis and Antibacterial Activity of $\mathrm{CuO}$ Nanoparticles Suspension Induced by Laser Ablation in Liquid. Arabian J. Sci. Eng. 2016, 41, 301-310.

(20) Mahapatra, O.; Bhagat, M.; Gopalakrishnan, C.; Arunachalam, K. D. Ultrafine Dispersed $\mathrm{CuO}$ Nanoparticles and Their Antibacterial Activity. J. Exp. Nanosci. 2008, 3, 185-193.

(21) Bondarenko, O.; Juganson, K.; Ivask, A.; Kasemets, K.; Mortimer, M.; Kahru, A. Toxicity of Ag, $\mathrm{CuO}$ and $\mathrm{ZnO}$ Nanoparticles to Selected Environmentally Relevant Test Organisms and Mammalian Cells in Vitro: A Critical Review. Arch. Toxicol. 2013, 87, 11811200.

(22) Bacchetta, R.; Moschini, E.; Santo, N.; Fascio, U.; Del Giacco, L.; Freddi, S.; Camatini, M.; Mantecca, P. Evidence and Uptake Routes for Zinc Oxide Nanoparticles through the Gastrointestinal Barrier in Xenopus Laevis. Nanotoxicology 2014, 8, 728-744.

(23) Bonfanti, P.; Moschini, E.; Saibene, M.; Bacchetta, R.; Rettighieri, L.; Calabri, L.; Colombo, A.; Mantecca, P. Do Nanoparticle Physico-Chemical Properties and Developmental Exposure Window Influence Nano $\mathrm{ZnO}$ Embryotoxicity in Xenopus Laevis? Int. J. Environ. Res. Public Health 2015, 12, 8828-8848.

(24) Midander, K.; Cronholm, P.; Karlsson, H. L.; Elihn, K.; Möller, L.; Leygraf, C.; Wallinder, I. O. Surface Characteristics, Copper Release, and Toxicity of Nano- and Micrometer-Sized Copper and Copper(II) Oxide Particles: A Cross-Disciplinary Study. Small 2009, 5, 389-399.
(25) Moschini, E.; Gualtieri, M.; Colombo, M.; Fascio, U.; Camatini, M.; Mantecca, P. The Modality of Cell-Particle Interactions Drives the Toxicity of Nanosized $\mathrm{CuO}$ and $\mathrm{TiO} 2$ in Human Alveolar Epithelial Cells. Toxicol. Lett. 2013, 222, 102-116.

(26) Semisch, A.; Ohle, J.; Witt, B.; Hartwig, A. Cytotoxicity and genotoxicity of nano - and microparticulate copper oxide: role of solubility and intracellular bioavailability. Part. Fibre Toxicol. 2014, 11, 10.

(27) Perelshtein, I.; Lipovsky, A.; Perkas, N.; Gedanken, A.; Moschini, E.; Mantecca, P. The Influence of the Crystalline Nature of Nano-Metal Oxides on Their Antibacterial and Toxicity Properties. Nano Res. 2015, 8, 695-707.

(28) Zhang, S.; Gao, H.; Bao, G. Physical Principles of Nanoparticle Cellular Endocytosis. ACS Nano 2015, 9, 8655-8671.

(29) Lee, Y. K.; Choi, E. J.; Webster, T. J.; Kim, S. H.; Khang, D. Effect of the Protein Corona on Nanoparticles for Modulating Cytotoxicity and Immunotoxicity. Int. J. Nanomed. 2015, 10, 97-113.

(30) Bastian, S.; Busch, W.; Kühnel, D.; Springer, A.; Meißner, T.; Holke, R.; Scholz, S.; Iwe, M.; Pompe, W.; Gelinsky, M.; et al. Toxicity of Tungsten Carbide and Cobalt-Doped Tungsten Carbide Nanoparticles in Mammalian Cells in Vitro. Environ. Health Perspect. 2009, 117, 530-536.

(31) Nagvenkar, A. P.; Deokar, A.; Perelshtein, I.; Gedanken, A. A One-Step Sonochemical Synthesis of Stable ZnO-PVA Nanocolloid as a Potential Biocidal Agent. J. Mater. Chem. B 2016, 4, 2124-2132.

(32) Hojo, N.; Shirai, H.; Hayashi, S. Complex Formation Between Poly(Vinyl Alcohol) and Metallic Ions in Aqueous Solution. J. Polym. Sci. 1974, 47, 299-307.

(33) Eliseev, A. A.; Lukashin, A. V.; Vertegel, A. A.; Heifets, L. I.; Zhirov, A. I.; Tretyakov, Y. D. Complexes of Cu (II) with Polyvinyl Alcohol as Precursors for the Preparation of $\mathrm{CuO} / \mathrm{SiO}_{2}$ Nanocomposites. Mater. Res. Innovations 2000, 3, 0308-0312.

(34) Applerot, G.; Lellouche, J.; Lipovsky, A.; Nitzan, Y.; Lubart, R.; Gedanken, A.; Banin, E. Understanding the Antibacterial Mechanism of $\mathrm{CuO}$ Nanoparticles: Revealing the Route of Induced Oxidative Stress. Small 2012, 8, 3326-3337.

(35) Applerot, G.; Lipovsky, A.; Dror, R.; Perkas, N.; Nitzan, Y.; Lubart, R.; Gedanken, A. Enhanced Antibacterial Activity of Nanocrystalline $\mathrm{ZnO}$ Due to Increased ROS-Mediated Cell Injury. Adv. Funct. Mater. 2009, 19, 842-852.

(36) Chang, Y.-N.; Zhang, M.; Xia, L.; Zhang, J.; Xing, G. The Toxic Effects and Mechanisms of $\mathrm{CuO}$ and $\mathrm{ZnO}$ Nanoparticles. Materials 2012, 5, 2850-2871.

(37) Ray, P. D.; Huang, B.-W.; Tsuji, Y. Reactive Oxygen Species (ROS) Homeostasis and Redox Regulation in Cellular Signaling. Cell. Signalling 2012, 24, 981-990.

(38) Hayyan, M.; Hashim, M. A.; AlNashef, I. M. Superoxide Ion: Generation and Chemical Implications. Chem. Rev. 2016, 116, 30293085.

(39) Li, Y.; Zhang, W.; Niu, J.; Chen, Y. Mechanism of Photogenerated Reactive Oxygen Species and Correlation with the Antibacterial Properties of Engineered Metal-Oxide Nanoparticles. ACS Nano 2012, 6, 5164-5173.

(40) Kohno, M. Applications of Electron Spin Resonance Spectrometry for Reactive Oxygen Species and Reactive Nitrogen Species Research. J. Clin. Biochem. Nutr. 2010, 47, 1-11.

(41) Schiek, M.; Al-Shamery, K.; Kunat, M.; Traeger, F.; Wöll, C. Water Adsorption on the Hydroxylated $\mathrm{H}-(1 \times 1) \mathrm{O}-\mathrm{ZnO}(0001)$ Surface. Phys. Chem. Chem. Phys. 2006, 8, 1505-1512.

(42) Tabah, B.; Nagvenkar, A. P.; Perkas, N.; Gedanken, A. SolarHeated Sustainable Biodiesel Production from Waste Cooking Oil Using a Sonochemically Deposited SrO Catalyst on Microporous Activated Carbon. Energy Fuels 2017, 31, 6228-6239.

(43) Fu, P. P.; Xia, Q.; Hwang, H.-M.; Ray, P. C.; Yu, H. Mechanisms of nanotoxicity: Generation of reactive oxygen species. J. Food Drug Anal. 2014, 22, 64-75.

(44) Kafil, V.; Omidi, Y. Cytotoxic Impacts of Linear and Branched Polyethylenimine Nanostructures in A431 Cells. Bioimpacts 2011, 1, 23-30. 
(45) Nguyen, J.; Xie, X.; Neu, M.; Dumitrascu, R.; Reul, R.; Sitterberg, J.; Bakowsky, U.; Schermuly, R.; Fink, L.; Schmehl, T.; et al. Effects of Cell-Penetrating Peptides and Pegylation on Transfection Efficiency of Polyethylenimine in Mouse Lungs. J. Gene Med. 2008, 10, 1236-1246.

(46) Li, Y.; Kröger, M.; Liu, W. K. Endocytosis of PEGylated Nanoparticles Accompanied by Structural and Free Energy Changes of the Grafted Polyethylene Glycol. Biomaterials 2014, 35, 84678478.

(47) Sanchez, L.; Yi, Y.; Yu, Y. Effect of Partial PEGylation on Particle Uptake by Macrophages. Nanoscale 2017, 9, 288-297.

(48) Suk, J. S.; Xu, Q.; Kim, N.; Hanes, J.; Ensign, L. M. PEGylation as a Strategy for Improving Nanoparticle-Based Drug and Gene Delivery. Adv. Drug Delivery Rev. 2016, 99, 28-51.

(49) Guaiquil, V. H.; Vera, J. C.; Golde, D. W. Mechanism of Vitamin C Inhibition of Cell Death Induced by Oxidative Stress in Glutathione-Depleted HL-60 Cells. J. Biol. Chem. 2001, 276, 4095540961.

(50) Ndiaye, M. A.; Nihal, M.; Wood, G. S.; Ahmad, N. Skin, Reactive Oxygen Species, and Circadian Clocks. Antioxid. Redox Signaling 2014, 20, 2982-2996.

(51) Bouzas, V.; Haller, T.; Hobi, N.; Felder, E.; Pastoriza-Santos, I.; Pérez-Gil, J. Nontoxic Impact of PEG-Coated Gold Nanospheres on Functional Pulmonary Surfactant-Secreting Alveolar Type II Cells. Nanotoxicology 2014, 8, 813-823.

(52) Alcantar, N. A.; Aydil, E. S.; Israelachvili, J. N. Polyethylene Glycol-Coated Biocompatible Surfaces. J. Biomed. Mater. Res. 2000, 51, 343-351.

(53) Mihai, C.; Chrisler, W. B.; Xie, Y.; Hu, D.; Szymanski, C. J.; Tolic, A.; Klein, J. A.; Smith, J. N.; Tarasevich, B. J.; Orr, G. Intracellular Accumulation Dynamics and Fate of Zinc Ions in Alveolar Epithelial Cells Exposed to Airborne $\mathrm{ZnO}$ Nanoparticles at the Air-Liquid Interface. Nanotoxicology 2015, 9, 9-22.

(54) Shen, C.; James, S. A.; de Jonge, M. D.; Turney, T. W.; Wright, P. F. A.; Feltis, B. N. Relating Cytotoxicity, Zinc Ions, and Reactive Oxygen in $\mathrm{ZnO}$ Nanoparticle-Exposed Human Immune Cells. Toxicol. Sci. 2013, 136, 120-130. 